\title{
LIVES DE FESTAS NOS TEMPOS DA COVID-19: ARRANJOS, VÍNCULOS E PERFORMANCES
}

- PATRÍCIA SILVA

https://orcid.org/0000-0002-9415-0629

Universidade Federal da Paraíba

DANILO MOTA LIMA

https://orcid.org/0000-0001-8118-147X

Universidade Federal da Bahia

EDVALDO SOUZA COUTO

https://orcid.org/0000-0002-2648-9399

Universidade Federal da Bahia

RESUMO Com a pandemia da COVID-19, fomos estimulados por governos e profissionais de saúde a ficar em casa, em isolamento fisico. Para as pessoas conectadas, o isolamento fisico não significa isolamento social. Nossas experiências ciberculturais são repletas de redes sociotécnicas que reconstroem e impulsionam a nossa vida social, sobretudo no contexto da pandemia, por meio, por exemplo, do fenômeno das lives. Nesse contexto, o objetivo do artigo é analisar arranjos, vínculos e narrativas gerados a partir das performances humanas e não humanas em uma live de uma festa virtual. 0 argumento central é que a live é uma pedagogia cultural que nos orienta a festejar a vida, cuidar do corpo, explorar outras possibilidades para a paquera e a sexualidade on-line, ao mesmo tempo em que continuamos a defender nossas pautas políticas e ativistas. 0 método usado foi o da pesquisa pós-qualitativa, por meio da estratégia da observação participante. Concluímos que as lives rapidamente se popularizaram como redes sociotécnicas dinâmicas, repletas de pedagogias culturais que nos ajudam a organizar a vida social em meio ao isolamento físico e que a live da Festa da resistência, com suas performances celebradas, mostra que reinventamos o social, agora na esfera do on-line, promovendo diversos hibridismos.

Palavras-chave: COVID-19. Pandemia. Live. Redes sociotécnicas. Pedagogias culturais. 
ABSTRACT LIVES IN THE PARTIES IN THE TIMES OF COVID-19:

\section{ARRANGEMENTS, LINKS AND PERFORMANCES}

With the COVID-19 pandemic, we were encouraged by governments and health professionals to stay at home, in physical isolation. For people connected, physical isolation does not mean social isolation. Our cybercultural experiences are full of sociotechnical networks that rebuild and boost our social life, especially in the context of the pandemic, through, for example, the phenomenon of lives. In this context, the objective of the article is to analyze arrangements, links and narratives generated from human and nonhuman performances in a live of a virtual party. The central argument is that live is a cultural pedagogy that guides us to celebrate life, take care of the body, explore other possibilities for online flirting and sexuality, while continuing to defend our political and activist agendas. The method used was that of post-qualitative research, through the participant observation strategy. With the study, we concluded that lives quickly became popular as dynamic sociotechnical networks, full of cultural pedagogies that help us organize social life in the midst of physical isolation and that the live of the resistance party, with its celebrated performances, shows that we reinvented the social, now in the sphere of online, promoting several hybridities.

Keywords: COVID-19. Pandemic. Live. Sociotechnical Networks. Cultural Pedagogies.

\section{RESUMEN FIESTAS EN VIVO EN LOS TIEMPOS COVID-19:}

\section{ARREGLOS, ENLACES Y ACTUACIONES}

Con la Covid-19, gobiernos y profesionales de la salud, nos animaron a permanecer en casa, en aislamiento físico que no significa aislamiento social. Nuestras experiencias ciberculturales están llenas de redes sociotécnicas que reconstruyen e impulsan nuestra vida social, especialmente en el contexto de la pandemia, a través del fenómeno de las transmisiones en vivo. El objetivo del artículo es analizar los arreglos, lazos y narrativas generados a partir de actuaciones humanas y no humanas en una transmisión en vivo de una fiesta virtual. El argumento central es que las transmisiones en vivo son una pedagogía cultural que nos guían a celebrar la vida, cuidar del cuerpo, explorar otras posibilidades para los encuentros amorosos y la sexualidad, mientras continuamos defendiendo nuestras agendas políticas y activistas. El método utilizado fue el de la investigación post-cualitativa, mediante de la estrategia de observación participante. Concluimos que las transmisiones en vivo se hicieron 
rápidamente populares como redes sociotécnicas dinámicas, llenas de pedagogías culturales que nos ayudan a organizar la vida social en medio del aislamiento físico y que la transmission de la fiesta de la resistencia, con sus actuaciones celebradas, muestra que reinventamos lo social, ahora en la esfera de lo online, promoviendo diversas hibridaciones.

Palabras clave: Covid-19. Pandemia. Transmisiones en Vivo. Redes Sociotécnicas. Pedagogías Culturales.

\section{Introdução}

Atualmente, a vivência na sociedade conectada demonstra que somos constituídos de vários elementos que nos moldam e nos associam ao mundo (LE BRETON, 2003; HARAWAY, 2009; COUTO, 2012). Ou seja, o humano é ao mesmo tempo uma singularidade e um somatório de vínculos.

Através de tecnologias digitais conectadas à rede, interagimos, brincamos, produzimos e consumimos. Esse fluxo informacional oferece novas rotas e narrativas para a percepção de mundo, principalmente no contexto da pandemia da COVID-19, no qual os indivíduos se unem às técnicas para construir novas formas de interação e desenvolver outros modos de ser.

Todos os setores estão sendo impactados com a pandemia: a educação, a saúde, a indústria cultural, só para ilustrar alguns. Eles estão se reinventando, seja com a utilização da telemedicina, das aulas on-line em plataformas específicas, ou ainda, com a popularização das lives, que são transmissões ao vivo de áudio e vídeo na internet, com objetivo principal de entretenimento, estabelecendo um canal de interatividade através da conexão direta com o público. A tendência que se observa é o crescimento na utilização das tecnologias como forma de romper com o isolamento físico, sem, contudo, transgredir as regras de distanciamento entre as pessoas, algo extremamente necessário.
Nesse contexto, o argumento que desenvolvemos neste artigo é que as tecnologias, os objetos/coisas, os não humanos, independente do sinônimo que usemos, exercem o papel de aumentar as nossas capacidades e os nossos sentidos. As tecnologias podem ser entendidas como um dispositivo de liberdade performativa, a fim de repensarmos as práticas sociais. Compreender como os objetos/coisas estão participando ativamente da vida social e como eles se associam aos humanos é essencial, pois possibilita perceber que as práticas sociais emergem de enredos entre os humanos e os não humanos. Um modelo exemplar desse enredo sociotécnico é a live, um fenômeno cibercultural da era da pandemia da COVID-19. O enredo aqui estudado é a live da Festa da resistência. Consideramos que a live é uma pedagogia cultural que nos orienta a festejar a vida, cuidar do corpo, explorar outras possibilidades para a paquera e a sexualidade on-line, ao mesmo tempo em que continuamos a defender nossas pautas políticas e ativistas. Sendo assim, o objetivo do artigo é analisar arranjos, vínculos e narrativas gerados a partir das performances humanas e não humanas em uma live de uma festa virtual chamada "Festa da resistência". Neste estudo, as lives são consideradas como fenômeno narrativo da nossa época pandêmica e como pedagogias culturais que orientam e constroem nossas subjetividades conectadas (CAMOZZATO; CAR- 
VALHO; ANDRADE, 2016). O campo empírico é a análise de uma live de uma festa virtual realizada em uma capital do Nordeste do Brasil, no dia 1o de maio de 2020. O método usado foi o pós-qualitativo, que tem como pressupostos teóricos o realismo agencial (BARAD, 2007), o poder das coisas (BENNETT, 2010) e as redes de multiplicidades (DELEUZE; GUATTARI, 1996).

Para a pesquisa pós-qualitativa, os fenômenos são descritos e explorados como arranjos e vínculos, como configurações sociomateriais do mundo, e qualquer ponto tem poder de ser conectado a qualquer outro, atuando como matéria viva na assembleia de humanos e/ou tecnológicas. Conforme Schatzki (2003), os objetos/coisas precisam ser incluídos também na análise de um fenômeno, pois eles compõem o processo pelo qual um dado fenômeno se desdobra. Assim, nos apropriamos do método etnográfico para seguir as coisas (LATOUR, 2012) e da observação participante para estudar o fenômeno da live escolhida.

\section{Tecnologias e COVID-19: formas de romper o isolamento físico}

Em 26 de fevereiro de 2020, chegou oficialmente ao Brasil o vírus SARS-CoV-2 e, desde então, estados e municípios têm incentivado o isolamento físico a fim de desacelerar o contato com o vírus e o desenvolvimento da doença associada a ele, a COVID-19. Com o auxílio de dispositivos conectados em rede, ao menos para os plenamente inseridos na cultura digital, passamos a viver em isolamento físico, mas não social. Nosso isolamento não significa perda de conexão com os outros.

Ao longo da história, o isolamento social tem sido utilizado como um potente recurso para o controle de contaminação de doenças infecciosas. Sua origem é atribuída à cidade de Veneza, que durante a Peste Negra, nos séculos XIV e XV, estipulou o confinamento de quaren- ta dias em seus portos. Durante esse período, os barcos deveriam permanecer isolados antes que seus passageiros e tripulantes desembarcassem. Surge daí a palavra "quarentena", eficiente medida para conter a propagação da Peste Negra e uma das práticas mais tradicionais de saúde pública (RAMOS, 2020).

No contexto da Peste Negra, o isolamento mantinha estreita relação entre flagelo e penúria, pois a quarentena significava confinamento social, físico e comunicacional. Atualmente, no contexto da sociedade conectada, o isolamento com o uso das tecnologias digitais permite diversas formas de socialização. 0 uso de dispositivos conectados em rede "mantém, de alguma forma, o vínculo coletivo. É isolamento físico, já que estamos confinados, mas conectados a outros [...]" (LEMOS, 2020; PRECIADO, 2020).

Se nas experiências das pandemias passadas o isolamento era um resguardo rigoroso e penoso, em tempos ciberculturais, as interações digitais se expandem, à medida que os dias em confinamento se acumulam. Estar em casa, agora, significa circular por ambiências do ciberespaço. Por meio de dispositivos conectados, construímos a nós mesmos e administramos nossa presença num mundo globalizado (COUTO; COUTO; CRUZ, 2020).

A cibercultura é resultado das experiências coletivas mediadas pelas tecnologias digitais conectadas em rede. Smartphones, computadores e tablets conectados à internet estruturam a cibercultura e nos dá a possibilidade de mantermos o convívio social, mesmo que remotamente, por meio dos dispositivos técnicos. Essas experiências conectivas, articuladas às mediações com diferentes ações humanas e não humanas, nos moldam e são moldadas por nossas experimentações cotidianas (OLIVEIRA; SANTOS, 2019).

Aplicativos como iFood, Rappi e Uber Eats levam o alimento na sua casa. O WhatsApp, Insta- 
gram e Twitter estimulam as interações sociais. Software e sites de videoconferências, como o Zoom Meetings, Jitsi Meet e Skype, permitem que universidades e escolas realizem eventos e continuem muitas das suas atividades, e que empresas mantenham a rotina de trabalho remotamente. Plataformas de streamings como Netflix, GloboPlay, Telecine Play e HBO GO mantêm o entretenimento e produção televisiva.

Esses cenários ganharam ainda mais força com a pandemia. Nesse meio-tempo, contribuindo para a interação social e o isolamento físico, surgem as lives, como mais um instrumento de interação. As lives, que em inglês significa "ao vivo", incentivam também a realização de shows e festas virtuais com data e hora marcada, em ambientes virtuais específicos. Elas são realizadas de maneira simples e eficiente, pois usualmente não estabelecem limites de participantes e nem tempo de exibição, e os usuários conectam-se por meio de computadores, tablets e celulares.

As lives estão imbricadas em um conjunto de arranjos e vínculos que contribuem diretamente para a constituição, o desenvolvimento e as narrativas dessas ações. Entendemos como arranjos e vínculos as arrumações e organizações das coisas no mundo, ou melhor, das partes que compõem o todo. São layout de humanos e não humanos que se relacionam e ocupam lugares em relação uns aos outros e se associam uns aos outros. As lives são importantes pedagogias culturais na pandemia.

0 conceito de pedagogias culturais surgiu no século XX com a implicação dos artefatos midiáticos na produção dos sujeitos, nas diversas esferas da vida e das instituições sociais. Esse termo explica que outros espaços, além da escola, funcionam como produtores de conhecimentos, saberes, formas de pensar e agir (ARROYO, 2012; GIROUX, 2018).

O conceito de pedagogia cultural indica que a educação ocorre:
[...] numa variedade de áreas sociais, incluindo, mas não se limitando à escolar. Áreas pedagógicas são aqueles lugares onde o poder é organizado e difundido, incluindo-se bibliotecas, TV, cinemas, jornais, revistas, brinquedos, propagandas, videogames, livros, esportes, etc. (STEINBERG; KINCHELOE, 2001, p. 14).

As interações ciberculturais abrem novos caminhos para as pedagogias culturais. 0 frequente acesso à internet propicia a abertura de novos meios de comunicação, sociabilidade e o estabelecimento de novas culturas que estruturam redes de produção de saberes, constroem formas específicas de práticas pedagógicas carregadas de significados, comportamentos e práticas interativas que difundem informações, signos e símbolos (COUTO, 2014).

As lives de festas, como pedagogias culturais, permitem novas experiências conectivas que ressignificam nossa sociabilidade. Em meio à pandemia do novo coronavírus, são celebrações importantes, um escape para esse momento amargo. Elas evocam memórias alegres e festivas, reforçam e constroem conexões.

As festas nas telas dos smartphones e computadores também elaboram e promovem estratégias de solidariedade e arrecadam doações para hospitais, instituições de pesquisa e comunidades carentes. As transmissões de grandes artistas arrecadam milhões de reais e toneladas de alimentos. A live realizada por Sandy e Junior, com pico de 2,5 milhões de pessoas assistindo, simultaneamente, arrecadou mil toneladas de alimentos e $\mathrm{R} \$ 1,8$ milhão em doações.

Nesse caminho de solidariedade em rede, diversas pessoas têm se organizado em ajudar pequenos artistas e produtores a sobreviver neste tempo de pandemia. Com pouca reserva financeira em comparação aos grandes artistas midiáticos, os artistas locais e de pequena audiência são os primeiros a sentir os efeitos econômicos causados pela pandemia do novo 
coronavírus. As lives são alternativas para essa dificuldade, fortalecem a economia solidária e contribuem com campanhas que valorizam e incentivam o consumo da arte local.

\section{Arranjos, vínculos e performances nas lives}

Observar que os seres humanos não estão totalmente no controle das práticas sociais, e em particular nas lives, nos parece interessante quando discutimos tais práticas, principalmente porque elas estão apoiadas na certeza de que os objetos/coisas também participam e contribuem para a formação delas. Isto é, entendemos que essas associações além de materializarem as relações humanas, também participam ativamente da vida social.

Ser social é associar-se, e estudar o social é estudar a associação em todas as suas formas materiais (DUIJN, 2009). O social é aquilo que se manifesta a partir das associações e como essas associações se estabilizam produzindo o social (LATOUR, 2012). Logo, o social é tudo que integra sujeitos/objetos/coisas e sem essa in- tegração não existiria sociedade, uma vez que as interações são realizadas por e através de objetos/coisas.

Quando pensamos uma live, dificilmente imaginamos as redes que se formam para a sua implementação, porque nossa vida social está cercada por tantas redes que passam a ser não visível ao olho humano. Geralmente, estamos tão completamente ligados a elas no cotidiano que sua relevância simbólica, subjetiva e social está imbricada em nós e nem percebemos a sua presença.

A palavra "rede" é frequentemente usada como sinônimo da palavra "internet", apesar das transformações que ocorreram ao longo dos anos (rede de computadores, rede social, rede elétrica etc.). Por isso, é importante ter em mente que "rede" é um termo mais amplo e que resulta em combinações híbridas, sendo assim, é mais apropriado chamarmos de "redes sociotécnicas". As redes sociotécnicas dizem respeito a um aglomerado de relações humanas com os objetos/coisas, mas que também envolvem discursos, imaginários, eventos etc., e a interação dessas partes complementares.

Figura 1 - Rede sociotécnica da Live Festa da resistência no App Zoom Meetings

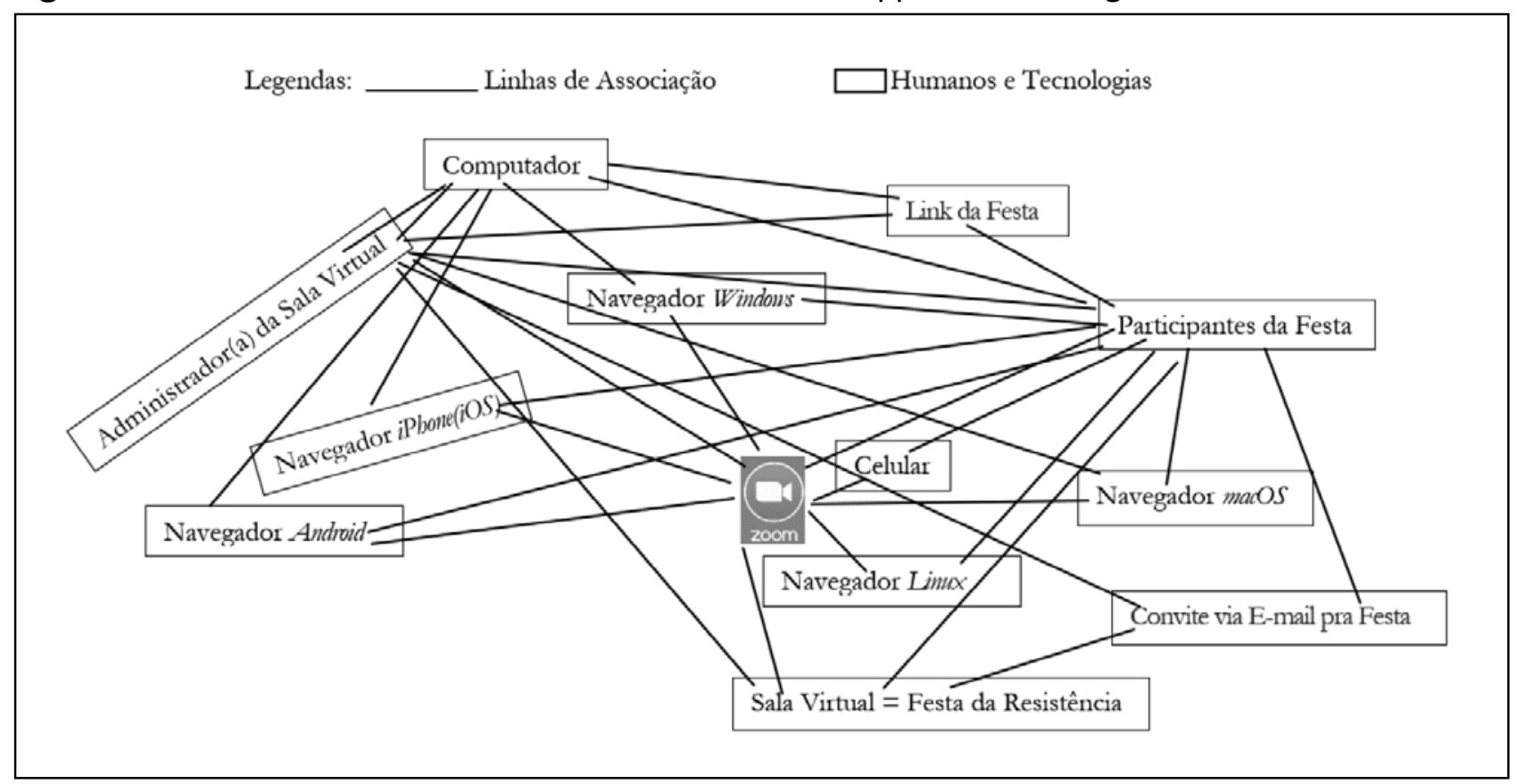

Fonte: elaborada pelos autores, 2020. 
Vejamos na Figura 1 a rede sociotécnica que envolve uma live. Para ilustrarmos, utilizamos a plataforma Zoom Meetings, que foi empregada na Festa da resistência e faz parte do corpus empírico do artigo. O Zoom Meetings é um aplicativo (App) da startup americana Zoom Video Communications, considerado um dos mais acessiveis em termos financeiros e de funcionalidades deste segmento. Está disponível para celulares e computadores e suporta reuniões com $n$ participantes (no serviço pago). O serviço funciona via navegador e em App para Windows, macOS, Linux, iPhone(iOS) e Android.

Na figura, humanos e não humanos são interligados entre si através de linhas de associação. No centro da rede, encontra-se o App Zoom Meetings. As linhas utilizadas representam a situação das relações existentes que podem ser: uma relação passada, aquela que já foi consolidada, como exemplo, o convite e o link enviado, e a relação atual, com a qual os atores humanos e não humanos estão estabilizados. Em qualquer desses movimentos, os atores da rede sociotécnica são representados.

A rede de atores humanos e tecnologias envolvidas na live da festa apresentam um clusters - logo do App Zoom Meetings -, que em termos sociotécnicos representa o elevado número de ligações, pois são motivados pelos mesmos interesses e, portanto, associados uns aos outros e, praticamente, a toda rede (ROSA; FERREIRA; SILVA, 2020).

Ao observar a rede sociotécnica, nenhuma entidade está isolada e nem apartada das outras, pois essas estão sempre emaranhadas em outras redes. É importante frisar que a rede é híbrida, ou seja, humanos e/ou não humanos não carecem ser definidos pela sua natureza, melhor dizendo, pelas suas características próprias e, sim, por meio de suas associações, interações e ações (HARMAN, 2009).

Outra característica é a de não termos como visualizar toda a rede, pois essa se desdobra em várias outras redes, explícitas ou não, e, consequentemente, influem em várias outras ações. Por exemplo, para o envio do link e convite via e-mail da festa, foi necessário a ação de uma outra rede, a Sympla: plataforma que conecta pessoas à realização da festa, possibilitando que organizadores criem, organizem, gerenciem e divulguem eventos.

Pelo exposto, podemos afirmar que foram os arranjos e vínculos que acarretaram transformaram, comunicaram as responsabilidades entre os envolvidos, que buscaram interesses próprios através de suas performances (BARBOSA, 2019; DELGADO; ANDRADE, 2018; LEMOS, 2013; LATOUR, 2000; CALLON, 1986).

Ao falar em performances nas lives, a primeira coisa que vem à mente é a atuação/ interpretação dos participantes da festa, pois estamos acostumados a pensar de um ponto de vista humanista, aquele que se concentra em diálogos horizontais de humanos com humanos, através da concepção do homem como locus de tudo, independentemente de todos os comportamentos não humanos medidos ou captados em termos de desempenho ou de atos performativos.

Quem performa, os participantes da festa ou as tecnologias utilizadas? A performance é o mecanismo através do qual todos, humanos e não humanos, se relacionam entre si, independentemente de quaisquer diferenças ou a real complexidade de suas estruturas. A performatividade é compreendida não como um ato, mas como uma prática nomeada e produzida pelo discurso (BUTLER, 2001), ela é condição sine qua non de todas as formas de relacionalidade (FLORÊNCIO, 2014).

As performances envolvem uma variedade de atores, em diferentes espaços, tempos e contextos. As tecnologias, como os humanos, também podem performar. Essas performances sociotécnicas produzem narrativas das nossas subjetividades conectadas. 


\section{Metodologia}

Enquanto pensarmos na natureza do humano como ser supremo, as tecnologias, os objetos/ coisas, os não humanos etc. não importarão metodologicamente na produção e análise de dados. Contudo, se percebermos humanos e tecnologias emaranhados, associados, fazendo as coisas acontecerem, diferentes formas de pensar e fazer pesquisas surgem como mais uma alternativa sob um termo abrangente chamado "pesquisa pós-qualitativa" (ST. PIERRE, 2018a; 2018b; LE GRANGE, 2018; ULMER, 2017; GERRARD; RUDOLPH; SRIPRAKASH, 2017). A pesquisa pós-qualitativa é, nesse sentido, pós-antropocêntrica. O protagonismo não é mais do humano, mas dos hibridismos do par humano-não-humano.

A pesquisa pós-qualitativa não possui um consenso conceitual, pois está estruturada em vários fundamentos, sejam eles: as redes sociotécnicas como um rizoma (DELEUZE; GUATTARI, 1996); o realismo agencial mostrando como as tecnologias são atores vitais do mundo (BARAD, 2007); e o poder dos objetos/coisas, como matéria vibrante (BENNETT, 2010).

Posto isso, caracterizamos a pesquisa aqui apresentada como empírica, de método pósqualitativo, com procedimento de produção e análise de dados através da observação participante. Assim, motivada pela pesquisa pós-qualitativa, consideramos trabalhar a etnografia sob a perspectiva das redes sociotécnicas.

A etnografia se fundamenta no contato que ocorre ou se efetiva entre sujeitos pesquisados e o seu objeto, ou seja, por um grupo social sob o qual o recorte analítico é feito. Ela é particularmente interessante porque através de sua insistência na espessura e descrição detalhada, como ponto de partida para a investigação, expõe a uma rique- za de informações não estruturadas (LONGO; ZACKA, 2019).

Assim, utilizando os preceitos e premissas da etnografia com distinção em sua execução, uma vez que não iremos nos concentrar apenas nos humanos e, sim, em toda rede sociotécnica, validamos o uso da Etnografia das Redes Sociotécnicas (ERS). A ERS viabiliza analisar o fenômeno pelo olhar dos participantes da rede, humano e não humano, introduzindo todos os atores. Ela é uma alternativa metodológica que propõe o mapeamento como uma maneira possivel de revelar articulações do fenômeno estudado.

\section{Resultados e análises}

As lives são um fenômeno da nossa vida cibercultural. Rapidamente elas se popularizaram. Artistas, professores e profissionais de diversas aéreas fazem transmissões on-line em vários ambientes da internet, especialmente em redes sociais digitais. Uma reportagem de Bozzo Junior (2020) indica que, no Brasil, 30 artistas fizeram 30 lives em três dias. Foram 30 horas de música. A série de apresentações fez parte do circuito \#PGMemCasa, organizado pelo Prêmio Grão de Música. O sucesso dessas lives de artistas foi acompanhado também das lives de festa. Versões on-line de festas consagradas animam quem está em casa e arrecadam doações para quem precisa, destaca Garçoni (2020).

Para nossa investigação, escolhemos uma live de festa. A live Festa da resistência aconteceu no feriado do trabalhador, no dia de $1^{\circ}$ maio de 2020 , entre $22 \mathrm{~h}$ e $2 \mathrm{~h}$. A proposta para realização da live teve como objetivo a manutenção e o funcionamento da casa que promoveu a festa - local de resistência às boates gourmets -, no período da pandemia da COVID-19 e, assim, colaborar com a manutenção do espaço underground, que funciona há 14 anos como uma pista alternativa numa capital 
do Nordeste. A dinâmica da Festa da resistência (Figura 2) girou em torno da apresentação de quatro Disc Jokey (DJ) femininas com estilos de músicas diferenciados.

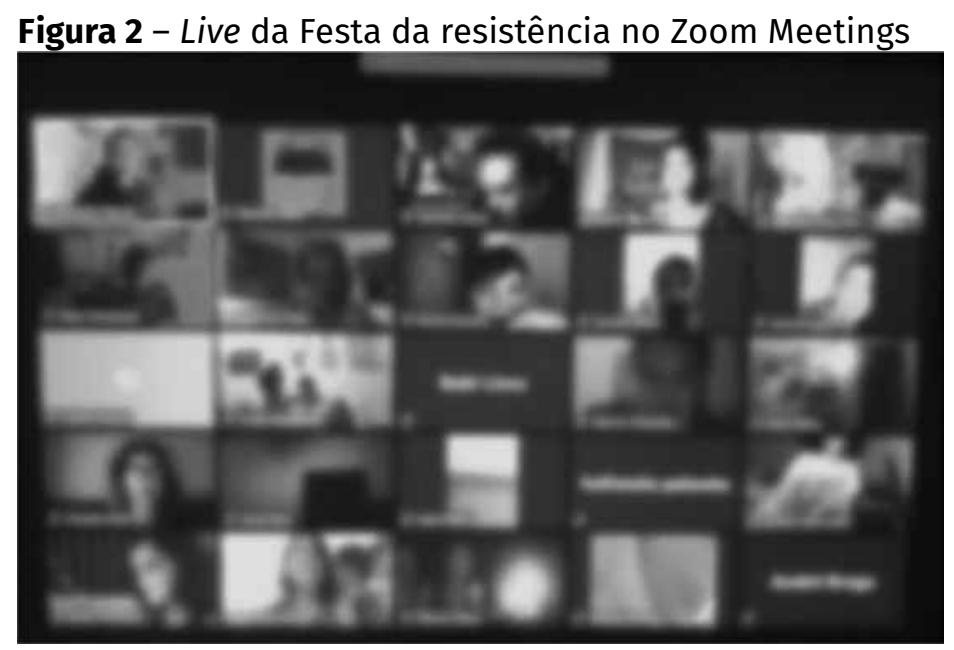

Fonte: elaborada pelos autores, 2020.

0 acesso à festa ocorreu mediante a compra de ingresso no valor de $\mathrm{R} \$ 5,00$ (cinco reais), na plataforma de eventos Sympla, já mencionada anteriormente. Após efetuar o pagamento, a Sympla enviava um convite com uma senha via e-mail e o link para os participantes da festa acessarem a plataforma Zoom Meetings. Observamos que cada componente da festa, seja esses humanos ou não, estavam agregados por vínculos e arranjos. Para participar da festa, precisávamos acessar a Sympla, mediante envio por e-mail e links, comprar o ingresso, ter o App Zoom Meetings instalado, entre tantos vínculos e arranjos.

Além da web conferência e compartilhamento em multitelas observadas na Figura 2, as interações se deram via chat pelo Zoom Meetings, sejam por meio de mensagens no privado com os participantes ou deixando curtidas, o que possibilitou a sociabilidade das 53 pessoas presentes, com faixa etária entre 2550 anos, residentes em Salvador, Recife, São Paulo, Brasília e Olinda. Desse total, 37 participaram com suas webcams ligadas e 16 mantiveram suas interações apenas por chat.

As multitelas da live, a ambientação do cenário que os participantes utilizavam para a construção dos cenários, auxiliavam na com- posição do visual performativo. Era possível vislumbrar bandeiras das diversas militâncias, sejam elas partidárias, do movimento marcha da maconha e do aborto livre e seguro, ou do ativismo de Lésbicas, Gays, Bissexuais, Transexuais, Queer, Intersexos (LGBTQI+). No ambiente, faziam usos de luzes especiais em tons de azul ou vermelho e de globos luminosos. Alguns participantes utilizaram software para fundo de tela, ambientando praias, saunas, universo sideral, entre outros.

Essas ações revelaram o desejo comum de mudança da aparência e da realidade física momentânea, o que de certo modo é facilitado pela cibercultura. Isso demonstra que o corpo é transformado em imagem e cuidadosamente elaborado para sua espetacularização.

As performances assumiram formas em diferentes espaços, tempos e contextos, envolvendo uma variedade de atores. Por exemplo, como performances, não humanas, podemos citar a plataforma Sympla, que enviou os e-mails e links para os humanos. É certo que a Festa da resistência objetivava alterar e estabelecer, pela ação do envolvimento entre humanos e tecnologias, os seus preceitos: a manutenção do espaço underground, em torno de uma prática constituí- 
da por forças sociais e materiais (pessoas, objetos/coisas, evento, plataformas, grupos, música etc.). Mas também se revelou como uma oportunidade para a produção do corpo em imagem.
Na Figura 3, um print do chat, no início da festa, revela a interação entre os participantes e a apresentação pessoal de alguns no que diz respeito à produção visual dos corpos feita para a live.

Figura 3 - Produção visual dos corpos

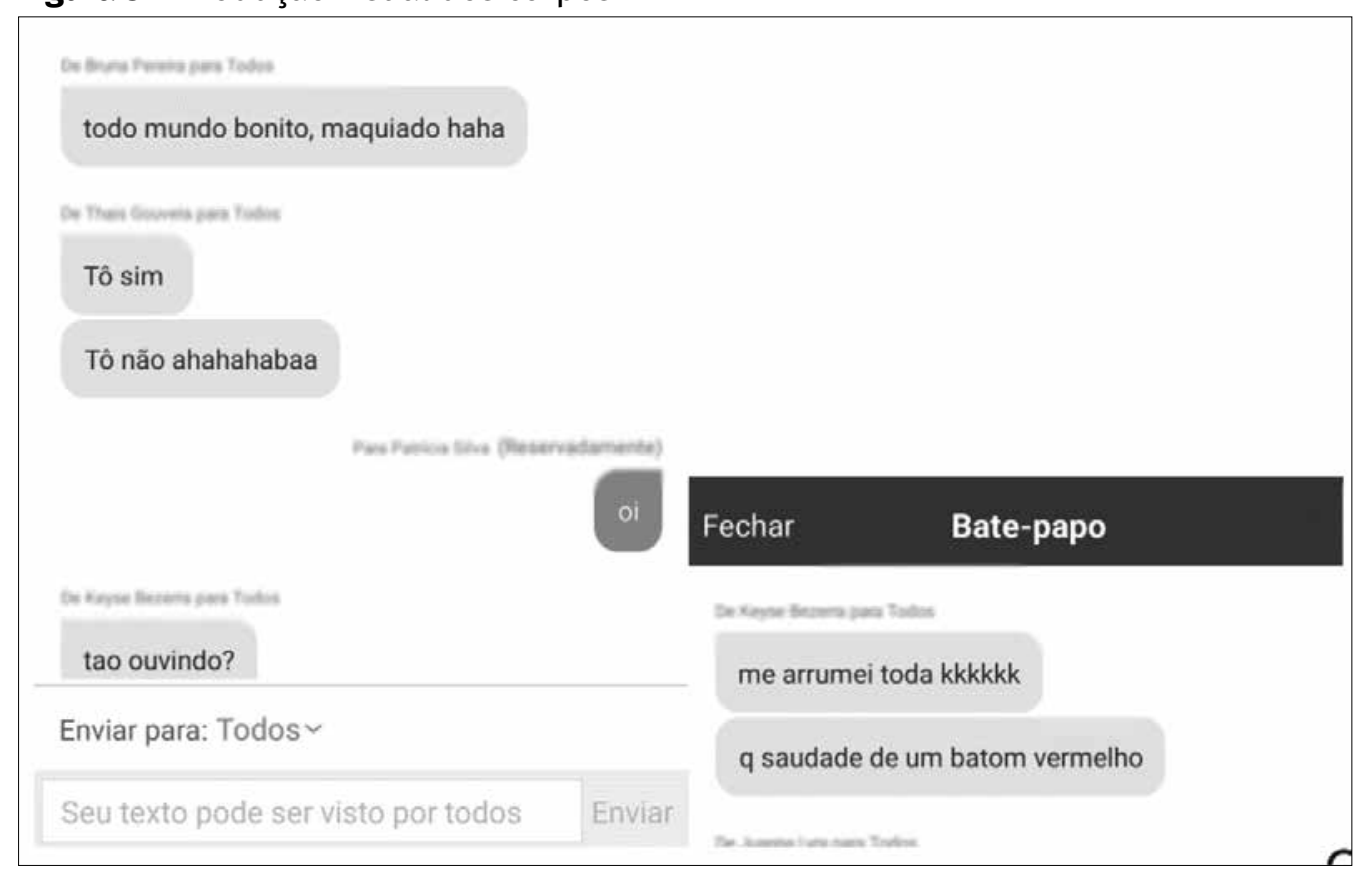

Fonte: elaborada pelos autores, 2020.

Dessa forma, os atributos visuais foram catalisadores no momento da comunicação entre as pessoas, o que fez do corpo um espaço de cuidados especiais sobre como ser e aparecer (COUTO, 2011). As potencialidades técnicas ofertadas pela live e pelos dispositivos modificaram a impressão das pessoas diante da sua própria aparência, favorecendo a construção de um outro corpo pela oferta de sua imagem pavoneada e compartilhada como elemento essencial da festa.

As modificações corporais como o uso do batom vermelho, o uso de máscaras, bandanas, roupas de festa, as posturas diante da webcam, o local e os objetos que compõem os cenários, associados à capacidade técnica do dispositivo usado - smartphone, tablet, notebook -, construíram a imagem dos participantes da festa.

A live da Festa da resistência também se constituiu como um local propício para paqueras on-line, conforme Figura 4. A paquera on-line é um fenômeno da cibercultura que foi superdimensionado com a pandemia. Governos de países como os Estados Unidos da América (EUA), Colômbia, Argentina, Inglaterra, França, Alemanha, Espanha, dentre outros, recomendaram que as pessoas buscassem a paquera on-line, a pornografia amadora ou profissional em rede e a masturbação, diante das câmeras e com transmissão direta ou em privado. A paquera on-line e a sexualidade on - line passaram a ser recomendadas como práticas seguras diante da transmissão acelerada do vírus da COVID-19 (COUTO; COUTO; CRUZ, 2020). Em outras palavras, essas recomendações de profissionais da saúde e de políticos estimularam a substituição da relação fisica por outras alternativas, como por exemplo o sexo virtual. 
A paquera on-line estimulou os participantes a conversaram sobre o envio de nudes. No App Zoom Meetings, existe a possibilidade de conversas privadas e de compartilhamento de arquivos de imagens entre os dispositivos, promovendo os prazeres sexuais.

Figura 4 - Paquera on-line.

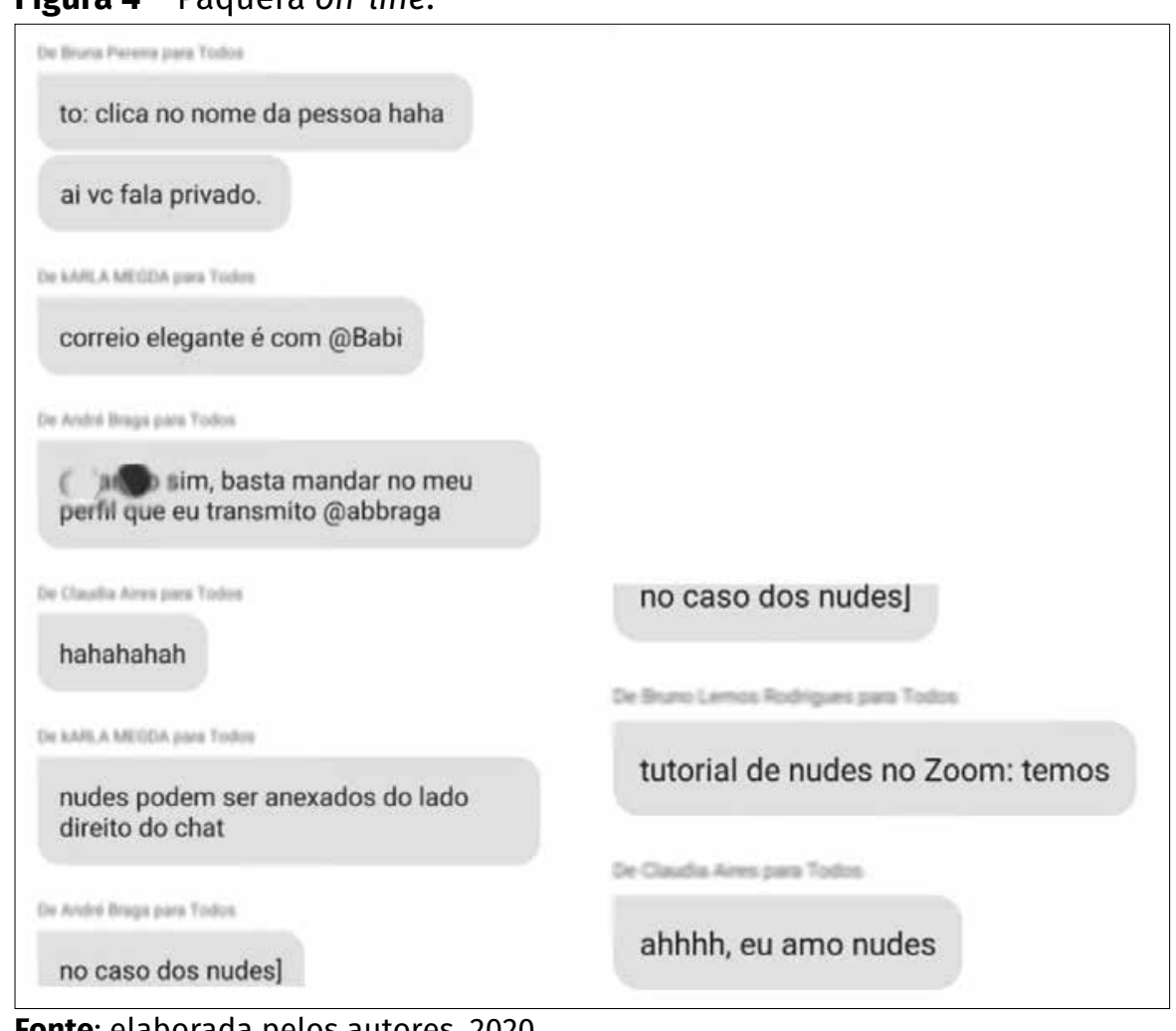

Na cibercultura, o humano se une à técnica para construir novas formas de interação com o sexo. 0 imbricamento do físico com o não físico gera novas performances de si através da datificação do corpo. Não é uma novidade o uso da internet para encontro afetivos e sexuais, mas no contexto da pandemia, a maioria das pessoas está aprendendo a utilizar as redes para rearticular e transformar essas relações. A live Festa da resistência ressaltou essas subjetividades aprendentes. Nesse contexto cibercultural, a troca de mensagens excitantes e os envios de nudes revelam os corpos e as sexualidades que não estão mais nos corpos e nas sexualidades, mas em suas representações, nas encenações, narrativas, discursos e performances visuais que circulam nos ambientes de rede.

Esses fenômenos que animam as trocas de afeto e do sexo em rede tornam nossas vi- das cada vez mais performativas e transfere a excitação e o gozo do corpo humano para representações e simulações. As performances sexuais circulam rapidamente para o consumo veloz e arrebatador do gozo ilimitado (LIMA; SILVA; COUTO, 2019).

Sobre a prática do sexo on-line durante o isolamento físico, Couto, Couto e Cruz (2020, p. 208) salientam que:

No nosso isolamento social, o cibersexo são artificios e textualidades compostos por sons, imagens fotográficas e videográficas, signos diversos que se misturam, se confundem e são re-mixados na produção de novos produtos para diferentes sentidos e gozos. Redes sociotécnicas cada vez mais elaboradas são destinadas às satisfações dos desejos.

Nesse sentido, quando os corpos estão em quarentena, para a segurança e preservação da saúde, o sexo se confunde com os jogos 
de linguagem, os signos, a publicidade e, sobretudo, pelas performances digitais. De acordo com as ontologias múltiplas de Mol (2002; 2008), as performances dos participantes, das tecnologias, dos cenários, da música etc., revelam interferências heterogêneas, entre elas: a performance técnica (Sympla, Zoom Meetings); a performance política (movimentos partidários, ativismos LGBTQI+, legalização da maconha, aborto legal e seguro); a performance humana (usar batom, roupa de festa). Ou seja, além de existir mediação entre as possiveis tensões políticas, também estão envolvidas questões técnicas e da realidade, mostrando que estão em jogo várias redes sociotécnicas que compõem os nossos corpos, as sexualidades diáfanas, os modos de ensinar e festejar a vida. A live como produto e fenômeno da cibercultura é repleta de pedagogias culturais, pois, com ela, ensinamos e aprendemos.

\section{Considerações finais}

O uso das tecnologias digitais conectadas à rede permitiu experiências que ressignificam nossas experimentações cotidianas em meio à pandemia da COVID-19, possibilitando vivermos em isolamento físico, mas não social. A era das conectividades permite que muitas pessoas permaneçam em suas casas e movimentam a sua vida social enquanto se preservam das relações presenciais, nesse momento, consideradas perigosas e fonte de contágio e adoecimento. As lives rapidamente se popularizaram como redes sociotécnicas dinâmicas que nos ajudam a organizar a vida social em meio ao isolamento físico. Elas surgem dos efeitos entre os vínculos e arranjos nas diversas redes de relações entre atores humanos e tecnológicos. Elas nos permitem visualizar novas dimensões, estruturas, reconhecer os atores e ações enredadas, bem como mostrar a complexidade das situações e interações envolvidas.
Não por acaso, as lives de artistas, professores e de muitos outros profissionais dos mais diversos campos foram seguidas das lives de festas virtuais. Nossos modos de organizar e participar de festas também mudaram de modo intenso com a pandemia. Sem a presença fisica, as festas se tornaram experiências de conectividades, por meio de transmissões ao vivo. Um modo fascinante de celebrar, entreter, paquerar e interagir com pessoas que constroem suas existências on-line em redes sociotécnicas. Essa condição traz novos desafios as nossas formas habituais de pensar o social, direcionando a atenção, também, aos não humanos, gerando novas práticas e experimentações. É a apropriação do não humano na análise social que gera participação nas ações em situações cotidianas, que provocam transformações.

Além dessas, nosso estudo permitiu um conjunto de outras conclusões das quais queremos ainda destacar: não existe um só momento em que não sejamos afetados por objetos/coisas, não temos como cair no mundo dos objetos/coisas, porque não há humanos sem esse mundo, ou seja, a história do material é desde o início parte e parcela da história humana. A live da Festa da resistência aponta que é por meio dos arranjos sociotécnicos que nossa vida cibercultural, para além da pandemia da COVID-19, acontece e cada vez mais acontecerá.

Outra conclusão é que somos agentes performativos. Nós fazemos coisas no mundo, mas o mundo também faz coisas em nós. É essa multiplicidade que precisa ser compreendida, pois as performatividades celebradas, como nesse caso da live da Festa da resistência, mostram que reinventamos o social, agora na esfera do on-line, promovendo diversos hibridismos entre humanos e não humanos. Esses hibridismos criam outras possibilidades festivas, políticas e educacionais para os corpos, os 
afetos, as sexualidades, o consumo, o divertimento e os ativismos. Esse conjunto de ações geram mais experiências e campos narrativos por meio dos quais continuamos a comemorar nossas vidas conectadas.

Por fim, concluímos também que as lives e a live da Festa da resistência, como fenômenos da vida em rede, contêm diversas pedagogias que orientam nossas redes de sociabilidade nesse momento crítico do isolamento físico durante a pandemia. Elas são e contêm pedagogias culturais quando nos estimulam e nos ensinam a construir estratégias para promover encontros em rede, pavonear os corpos e as sexualidades em ambientes digitais, encontrar formas prazerosas e seguras de mesclar o divertimento e o gozo com as nossas pautas e conquistas educacionais e políticas. É possivel que essas performances se espalhem por meio de uma multiplicidade de narrativas capazes de nos orientar para o bem viver e bem conviver também na pós-pandemia.

\section{REFERÊNCIAS}

ARROYO, Miguel. Outros sujeitos, outras pedagogias. Petrópolis: Vozes, 2012.

BARAD, Karen. Meeting the universe halfway. Quantum physics and the entanglement of matter and meaning. 2007. Disponivel em https://smartnightreadingroom.files.wordpress.com/2013/05/ meeting-the-universe-halfway.pdf. Acesso em: 24 jul. 2019.

BARBOSA, Saionara Aparedida. Mapeando as controvérsias que envolvem o processo de medicalização da infância. Psicol. Soc., Belo Horizonte,v. 31,p. 1-14, 2019.

BENNETT, Janett. Thing-Power. In: BRAUN, B.; WHATMORE, S. J. Political Matter: Technoscience, Democracy, and Public Life. Minnesota: University of Minnesota Press, 2010. p. 35-62.

BOZZO JUNIOR, Carlos. Trinta artistas fazem trinta lives em três dias. Folha de São Paulo, 26/05/2020.
Disponivel em https://musicaemletras.blogfolha. uol.com.br/2020/05/26/trinta-artistas-fazem-trinta -lives-em-tres-dias/. Acesso em: 27 maio 2020.

BRAUN, Bruce; WHATMORE, Sarah. The Stuff of Politics: An Introduction. In: BRAUN, B.; WHATMORE, Sarah. Political Matter: Technoscience, Democracy, and Public Life. Minnesota: Univerversity of Minnesota Press, 2010. p. Ix-xl.

BUTLER, Judith. Corpos que pesam: sobre os limites discursivos do "sexo". In: LOURO, G. L. (org.). 0 corpo educado: pedagogias da sexualidade. 2. ed. Belo Horizonte: Autêntica, 2001. p..152-172.

CALLON, Michel. Some elements of a sociology of translation: domestication of the scallops and the fishermen of St Brieuc Bay. 1986. Disponivel em: https://www.researchgate.net/publication/238754296_Some_Elements_of_A_Sociology_of_Translation_Domestication_of_the_Scallops_ and_the_Fishermen_of_St_Brieuc_Bay. Acesso em: 20 fev. 2019.

CAMOZZATO, Viviane; CARVALHO, Rodrigo; ANDRADE, Paula. (Org.). Pedagogias culturais: a arte de produzir modos de ser e viver na contemporaneidade. Curitiba: Appris, 2016.

COUTO, Edvaldo. Souza. Corpos voláteis, corpos perfeitos: estudos sobre estéticas, pedagogias e políticas do pós-humano. Salvador: Edufba, 2012.

COUTO, Edvaldo Souza. Pedagogia das conexões: compartilhar conhecimentos e construir subjetividades nas redes sociais digitais. In: PORTO, Cristiane.; SANTOS, Edmeia. (Org.). Facebook e educação: publicar, curtir e compartilhar. Campina Grande: EDUEPB, 2014. p. 47-66. Disponivel em: https://static.scielo.org/scielobooks/c3h5q/pdf/porto-9788578792831.pdf. Acesso em: 26 mai. 2020.

COUTO, Edvaldo Souza; COUTO, Edilece.; CRUZ, Ingrid. \#Fiqueemcasa: Educação na Pandemia da Covid-19. Revista Interfaces Científicas. v. 8, n. 3, 2020. Disponivel em: https://periodicos.set.edu.br/index. php/educacao/article/view/8777. Acesso em: 20 maio 2020.

DELEUZE, Gilles; GUATTARI, Felix. Mil platôs - capitalismo e esquizofrenia. Rio de Janeiro: 34, 1996. V. 3. 
DELGADO, Anna Karenina Chaves; ANDRADE, Jackeline Amantino. Teoria Ator-Rede (TAR) como instrumento de pesquisa em turismo: buscando aproximações e contribuições. Revista Turismo - Visão e Ação, v. 21, n. 1, p. 144-164, 2019.

DOLWICK, Jim. The Social and Beyond: Introducing Actor-Network Theory. J Mari Arch, v. 4, p. 21-49, 2009.

DUIJN, Michael. Network Society and Public Policy Networks. In: DUIJN, Michael. Embedded Reflection on Public Policy Innovation: A Relativist/Pragmatist Inquiry into the Practice of Innovation and Knowledge. [S.l]: Eburon Academic Publishers, 2009. p. 7984. Disponivel em: http://ebookcentral.proquest. com/lib/bcufpb-ebooks/detail.action?doc. Acesso em: 10 fev. 2017.

FLORÊNCIO, João. Ecology Without Nature, Theatre Without Culture Towards an Object-Oriented Ontology of Performance. O-Zone: A Journal of Object-Oriented Studies, v. 1, p. 118-127, 2014.

GARÇONI, Ines. Versões online de festas consagradas animam quem está em casa e arrecadam fundos para quem precisa. 0 Globo, 26/05/2020. Disponivel em: https://oglobo.globo.com/ela/gente/ versoes-on-line-de-festas-consagradas-animamquem-esta-em-casa-arrecadam-doacoes-paraquem-precisa-24444543. Acesso em: 27 maio 2020.

GERRARD, Jessica.; RUDOLPH, Sophie.; SRIPRAKASH, Arathi. The Politics of Post-Qualitative Inquiry: History and Power. Qualitative Inquiry,v. 23, n. 5, p. 384-394, 2017.

GIROUX, Henry. Education in unsettling times: public intellectual and promise of cultural studies. In: GIROUX, Henry. Power/knowledge/pedagogy:the meaning of democratic education in unselttling times. Taylor e Francys Group Online, 2018. Disponível em: www.taylorfrancis.com/books/e/9780429966613/ chapters/10.4324\%2F9780429498060-2. Acesso em: 26 maio 2020.

HARAWAY, Donna. Manifesto ciborgue: Ciência, tecnologia e feminismo-socialista no final do século XX. In: HARAWAY, D.; KUNZRU, H.; TADEU, T. (Org.). Antropologia do ciborgue:as vertigens do pós-huma- no. 2 ed. Belo Horizonte: Autêntica, 2009, p. 33-118.

HARMAN, Graham. Prince of networks: Bruno Latour and metaphysics. Melbourne: Re. Press, 2009.

HENRIQUE, Trazíbulo. Covid-19 e a Internet (ou Estou em isolamento social físico). Revista Interfaces Cientificas - Humanas e Sociais, v.8, n. 3, 2020. Disponivel em: https://periodicos.set.edu.br/ index. php/humanas/article/view/8713. Acesso em: 20 maio 2020.

LATOUR, Bruno. Ciência em ação: como seguir cientistas e engenheiros sociedade afora. São Paulo: Unesp, 2000.

LATOUR, Bruno. Reagregando o Social: uma introdução à teoria do Ator-rede. Salvador: Edufba, 2012.

LE BRETON, David. Adeus ao corpo: antropologia e sociedade. Campinas: Papirus, 2003.

LE GRANGE, Levy. What is (post)qualitative research? South African Journal of Higher Education, v. 32, n. 5, p. 1-14, 2018.

LEMOS, André. Coronavírus: isolamento digital é um luxo para poucos em um país de miseráveis. Jornal Correio. Disponivel em: https://www.correio24horas.com.br/noticia/nid/coronavirus-isolamento-digital-e-um-luxo-para-poucos-em-um-pais-de-miseraveis/. Acesso em: 20 maio 2020.

LEMOS, André. A comunicação das coisas: teoria ator-rede e cibercultura. São Paulo: Annablume, 2013.

LIMA, Danillo Mota; SILVA, Patrícia.; COUTO, Edvaldo Souza. Pedagogias sexuais na cibercultura: o protagonismo do par humano-não-humano. In: PORTO, C.; OLIVEIRA, K.; CHAGAS, A. (Org.). EDUCIBER: Dilemas e práticas contemporâneas. Aracaju: EDUNIT, 2019 , v. 1, p. 65-84.

LONGO, Matthew; ZACKA, Bernardo. Political Theoryin an Ethnographic Key. American Political Science Review, v. 113, n. 4, p. 1066-1070, 2019.

MOL, Annemarie. Política ontológica: algumas ideias e várias perguntas. 2008. Disponível em: https://pure.uva.nl/ws/files/899834/77537_310751. pdf. Acesso em: 8 jan. 2018. 
MOL, Annemarie. The Body Multiple: Ontology in MedicalPractice.London, Duke University Press, 2002. Disponivel em: https://edisciplinas.usp.br/ pluginfile.php/4621896/mod_resource/content/2/ MOL\%2C\%20Annemarie.\%20The\%20body\%20multiple.pdf. Acesso em: 15 dez. 2019.

NIMMO, Richie. Actor-network theory and methodology: social research in a more-than-human world. Methodological Innovations Online, v. 6, n. 3, p. 108119, 2011.

OLIVEIRA, Kaio; SANTOS, Isabella. A ressaca da internet e os desafios atuais da cibercultura: uma crítica para além da inclusão digital. In: PORTO, Cristiane; OLIVEIRA, Kaio.; CHAGAS, Alexandre. (Org.). EDUCIBER: Dilemas e práticas contemporâneas. Aracaju: EDUNIT, 2019, v. 1, p. 21-32.

PICKERING, Andrew. Living in the material world. In: DE VAUJANY, F.X.; MITEV, N. (Eds). Materiality and Space. Technology, Work and Globalization. London: Palgrave Macmillan, 2013. p. 25-40.

PRECIADO, Paul. Aprendiendo del virus. In: AMADEO, Paul. (Ed.). Sopa de Wuhan. Madrid: ASPO (Aislamiento Social Preventivo y Obligatorio), 2020, p. 163-185.

RAMOS, Diana. Quarentena e Isolamento: A Peste Negra e a origem da Quarentena em Veneza. Biblioteca Nacional, 2020. Disponivel em: https://www. bn.gov.br/acontece/noticias/2020/04/quarentena-isolamento-peste-negra-origem-quarentena. Acesso em: 20 maio 2020.
ROSA, Luciane Oliveira; FERREIRA, Valéria Silva; SILVA, Sandra Cristina Vanzuita. Elaboração e análise de redes de política. Revista de Estudios Teóricos y Epistemológicos en Política Educativa, v. 5, p. 1-12, 2020.

SCHATZKI, Theodore. A new societist social ontology. Philosophy of the Social Sciences, v. 33, n. 2, p. 174-202, 2003.

ST. PIERRE, Elizabeth Adams. Writing Post Qualitative Inquiry. Qualitative Inquiry, v. 24, n. 9, p. 603-608, 2018a.

ST. PIERRE, Elizabeth Adams. Uma história breve e pessoal da pesquisa pós-qualitativa: em direção à "pós-investigação". Práxis Educativa, Ponta Grossa, v. 13, n. 3, p. 1044-1064, set./dez. 2018b. Disponível em: https://www.revistas2.uepg.br/index.php/ praxiseducativa. Acesso em: 5 jan. 2019.

STEINBERG, Shirley; KINCHELOE, Joel. (Orgs.). Cultura infantil: a construção corporativa da infância. Rio de Janeiro: Civilização Brasileira, 2001.

ULMER, Jasmine. Posthumanism as research methodology: inquiry in the Anthropocene. International Journal of Qualitative Studies in Education, 2017. Disponivel em: http://www.ufrpe.br/sites/www.ufrpe.br/files/ulmer_2017._posthumanism_as_research.pdf. Acesso em: 4 out. 2019.

Recebido em: 30/05/2020 Aprovado em: 10/08/2020

Patrícia Silva é doutora em Educação pela Faculdade de Educação da Universidade Federal da Bahia (UFBA). Mestre em Ciência da Informação pela Universidade Federal da Paraíba (UFPB). Professora adjunta do Departamento de Ciência da Informação da UFPB. Membro dos Grupos de Pesquisa Educação, Redes Sociotécnicas e Culturas Digitais (Edutec) e do Educação, Comunicação e Tecnologias (GEC) da UFBA, e do Grupo de Pesquisa Tecnologias Intelectuais (LTi) da UFPB. E-mail: silva.131313@gmail.com

Danilo Mota Lima é doutorando em Educação no Programa de Pós-Graduação em Educação da Universidade Federal da Bahia (UFBA). Membro dos Grupos de Pesquisa Educação, Redes Sociotécnicas e Culturas Digitais (Edutec) e Educação, Comunicação e Tecnologias (GEC) da UFBA. E-mail: lima.danillom@gmail.com

Edvaldo Souza Couto é pós-doutorado em Educação pela Universidade Federal do Rio Grande do Sul (UFRGS). Doutorado em Educação pela Universidade Estadual de Campinas (Unicamp). É professor titular no departamento de Educação II, na Faculdade de Educação, da Universidade Federal da Bahia (UFBA), onde atua na graduação e pós-graduação. Bolsista de Produtividade do Conselho Nacional de Desenvolvimento Científico e Tecnológico (CNPq) - PQ2. É líder do Grupo de Pesquisa Educação, Redes Sociotécnicas e Culturas Digitais (Edutec) e um dos coordenadores do Grupo de Pesquisa Educação, Comunicação e Tecnologia (GEC) da UFBA. E-mail: edvaldo@ufba.br 